\title{
Dictionarium Valachico-Latinum, primul lexicon bilingv original din scrisul românesc
}

\author{
Gheorghe Chivu* \\ Facultatea de Litere, Universitatea din București, Str. Edgar Quinet 5-7, Sector 1, 010017 București, România \\ Academia Română, Calea Victoriei 125, Sector 1, 010071 București, România
}

\section{Despre articol}

Istoric:

Primit 14 septembrie 2021

Acceptat 25 septembrie 2021

Publicat 12 decembrie 2021

Cuvinte-cheie:

filologie

editarea textelor

documente vechi

\begin{abstract}
Rezumat
Dictionarium Valachico-Latinum, text scris în zona Banat-Hunedoara la mijlocul veacului al XVII-lea, ocupă o poziție aparte în rîndul vechilor scrieri lexicografice românești. Acest prim dicționar original al limbii române, realizat foarte probabil pentru prezentarea unui corpus reprezentativ din vocabularul limbii române prin intermediul echivalentelor din limba latină, utilizează pentru prima dată modelul latinesc de organizare și de prezentare a cuvintelor selectate. Autorul textului, foarte bun cunoscător al limbii române, deopotrivă în varianta sa literară și în cea vorbită, urmînd același model latinesc, creează grafeme pentru redarea unor sunete specifice limbii române și recomandă forme și grafii, ca formă incipientă de normare literară și ca modalitate de organizare lexicografică.
\end{abstract}

\section{Considerații preliminare}

Vechile lucrări lexicografice românești ${ }^{1}$ sinnt, din păcate, puțin cunoscute chiar în rîndul specialiștilor. Am în vedere nu atît inventarul lexical, fișat (chiar dacă nu integral și nici după cele mai bune surse) pentru dicționarele istorice ale limbii noastre, cît scrierile propriu-zise din care a fost extras acest inventar și, mai ales, relația pe care aceste prime lexicoane au avut-o cu mediul cultural al epocii; pentru că notarea unui cuvînt sau consemnarea unui sens într-o lucrare de tip lexicografic oferă indicii semnificative asupra culturii alcătuitorului acelui text sau asupra modelului, respectiv a sursei acestuia, iar unele forme sau chiar unele grafii pot sugera sau argumenta atitudinea vechilor autori, traducători sau copiști de texte față de limba noastră de cultură și uneori chiar față de norma literară a vremii.

În aceste condiții, prezentul Workshop internațional de lexicografie, la care participă lingviști ce reprezintă țări şi ilustrează culturi diferite din centrul şi din sud-estul Europei, este bine venit. Urmare a cercetărilor ce vor fi prezentate și a discuțiilor ce se vor purta, întîlnirea și oscilația dintre modelul cultural răsăritean și cel apusean, dintre sursele slavone și cele de expresie latină sau, uneori, interferența celor două modele în cadrul vechilor noastre lexicoane, interferență specifică spațiului românesc, vor fi, cu siguranță, mai bine înţelese și mai atent ilustrate.

În această perspectivă, voi selecta cele mai semnificative date privind plasarea în timp, structura și caracteristicile primului lexicon bilingv original cunoscut din scrisul vechi românesc, intitulat de autor Dictionarium Valachico-Latinum ${ }^{2}$. Pînă spre finele secolului al XVIII-lea, acest lexicon, numit în mod curent Anonymus Caransebesiensis ${ }^{3}$, a fost de altfel singurul lexicon cu bază limba română de care avem știință.

*Adresă de corespondență: gheorghe.chivu@gmail.com.

${ }^{1}$ Vezi, pentru prezentarea acestora, Seche (1966, p. 7-33) și, mai recent, Iordan (1978, p. 13-17).

${ }^{2}$ Informațiile prezentate în continuare pot fi regăsite, însoțite de argumente detaliate, în Chivu (2008).

${ }^{3}$ Numele, dat de Crețu (1898), care a elaborat prima ediție integrală a textului, a scos din uz numele mai vechi, Anonymus Lugoshiensis, atribuit lexiconului de către Hasdeu (1891), descoperitorul și primul cercetător al manuscrisului. 


\section{Scurte considerații filologice}

Manuscrisul din care face parte Dictionarium Valachico-Latinum a fost descoperit în urmă cu 150 de ani de către Bogdan Petriceicu Hasdeu, în fondurile Bibliotecii Universităţii din Budapesta ${ }^{4}$. Potrivit catalogului marii biblioteci (Catalogus 1889, p. 194), în colecțiile sale se păstrează, sub cota H.3, un Dictionarium Valachico-Latino-Hungarico, nume înșelător, întrucît prima parte a miscelaneului indicat (paginile 1-173) cuprinde, după cum stă scris chiar pe prima pagină a lexiconului acum în discuție, doar două coloane, prima consacrată formelor-titlu românești, iar a doua echivalentelor latinești ale acestora ${ }^{5}$. Adaosurile maghiare, care ar putea să justifice caracterul (presupus) trilingv al textului, disparate și foarte puțin numeroase, fără să poată constitui o a treia coloană a lexiconului ${ }^{6}$, sînt datorate unui posesor ulterior al miscelaneului și datează cu siguranță de la începutul veacului al XVIII-lea. Atunci a fost ataşat lexiconului româno-latin (mai vechi și existînd multă vreme ca text independent ${ }^{7}$ ) grupul de file pe care erau notate, prin selecție din diverse surse latinești, mai multe Connotationes ex adagiis (p. 174-354). Pe două dintre ultimele file ale acestei a doua componente a manuscrisului înregistrat la Biblioteca Universității din Budapesta sub cota $H .3$ (p. 349-352), un posesor anonim, foarte probabil preot catolic, a făcut consemnări pentru un Itinerarium, notații din timpul unei vizitaţii întreprinse în localități din sudul Transilvaniei în anul 1742.

Dictionarium Valachico-Latinum, considerat pe bună dreptate de Bogdan Petriceicu Hasdeu „cel mai vechi dicționar al limbei române”, este deci un amplu lexicon bilingv cu baza limba română (numără 5292 de intrări), urmat de un mic glosar latin-român, organizat tematic în Frumenti et leguminum species, Os, oris şi Colores, ambele lucrări de tip lexicografic fiind scrise de aceeași mînă.

Autorul acestui Dictionarium, un intelectual exersat în scrierea textelor românești (după cum arată ductul îngrijit și sigur al literelor), cunoștea foarte bine limba latină. (Sînt identificate prin echivalente latinești nu doar cuvinte uzuale, general cunoscute, ci și lexeme cu semnificații, respectiv cu utilizări speciale, uneori chiar elemente de tip familiar sau argotic, regionalisme sau nume de plante cu circulaţie restrînsă.) El a operat numeroase modificări în prima formă transcrisă, corectînd mai multe cuvinte-titlu, adăugînd articole pe marginea din dreapta a paginii, anulînd o serie de intrări care se repetau, schimbînd locul altora pentru a corespunde ordinii alfabetice, completînd sau înlocuind unele glose latinești. Sînt toate acestea dovezi ale unei revizii făcute chiar de alcătuitorul lexiconului, cîteva adăugiri (se află în această situație grupuri cuprinzătoare de forme-titlu) sugerînd ipoteza introducerii formelor inițial omise nu de pe o redactare preliminară, reprodusă nu suficient de atent, ci de pe seturi de fișe ordonate alfabetic.

Analiza filigranologică a părţii mai vechi a miscelaneului arată că Dictionarium Valachico-Latinum a fost scris în jurul anului $1650^{8}$. Potrivit opiniei formulate de B.P. Hasdeu, descoperitorul și primul exeget al textului, dicţionarul era datat, pe baza analizei limbii, în ultimele decenii ale secolului al XVII-lea, în vreme ce Grigore Crețu, autorul primei ediții integrale a textului, îl plasa, urmînd fidel argumentația lui Hasdeu, „pe la 1670”, iar Tagliavini (1930, p. 10) se gîndea la „primii ani ai secolului al XVIII-lea”, făcînd probabil o corelație cu epoca de redactare a aşa-numitului Lexicon Marsilian.

O serie de particularități lingvistice (fonetisme dialectale bănățene și cuvinte cu circulație în zona Banat-Hunedoara), utilizarea ortografiei maghiare pentru scrierea cuvintelor românești, precum și consemnarea ca intrări separate a mai multe toponime din colțul sud-vestic al României dovedesc că textul a fost alcătuit, cum s-a afirmat încă de la începutul secolului al XX-lea, în zona Caransebeșului (sau, cum

\footnotetext{
${ }^{4}$ Vezi Hasdeu (1871).

${ }^{5}$ În două forme preliminare ale catalogului Bibliotecii, redactate în 1850 (Catalogus manuscriptorum <Bibliothece Regie Scientiarum Universitatis $>$, confectus circa annum 1850), respectiv în 1877 (Catalogus manuscriptorum qux in Regie Scientiarum Universitatis Bibliothece Archivio Pestini observantur), manuscrisul este consemnat sub numele corect, Dictionarium ValachicoLatinum.

${ }^{6}$ Vezi pentru acestea Chivu (2008, p. 8).

${ }^{7}$ Arată aceasta aspectul filelor de început și de sfîrșit ale lexiconului româno-latin.

${ }^{8}$ Vezi detalii la Chivu (2003, p. 21-27).
} 
nota Bogdan Petriceicu Hasdeu, în „cercul” Lugojului).

Alcătuitorul lexiconului, un învățat rămas (deocamdată) anonim (comparația cu scrisul unor învățați ai vremii, precum Ștefan Fogarasi sau Ioan Viski, nu a dat rezulatele așteptate), identificat conjunctural (dar neconvingător) de către unii cercetători cu Mihail Halici ${ }^{9}$, a aparținut deci mișcării culturale bănățene, ilustrate, în secolele al XVII-lea și al XVIII-lea, prin mai multe manuscrise în care a fost utilizat alfabetul latin.

Modelul principal urmat de autorul acestui prim dicționar românesc original l-a constituit cu siguranță un lexicon cu bază latinească. Sugerează utilizarea unui astfel de model în primul rînd modul de notare a formelor-titlu verbale (înregistrate sub forma de persoana I a indicativului prezent), dar spre aceeaşi idee trimite și modificarea formei, respectiv a ordinii cîtorva intrări. Va fi fost acest model lexicografic o ediție a cunoscutului Lexicon Latino-Greco-Hungaricum alcătuit de Albert Szenczi Molnár? Foarte probabil. Autorul, elaborînd un lexicon cu bază limba română și nu traducînd o sursă preexistentă, a consultat, cu siguranță, diverse lexicoane care circulau în epocă. Din paginile acestora a extras nu doar echivalente latinești ale cuvintelor-titlu românești, ci și cuvinte și forme românești ce caracterizau, în jurul anului 1650, alte variante literare decît cea bănățean-hunedoreană. Ne referim la intrări precum bostan, bute, ciobotar, ginere, nasture sau omăt. Unele dintre aceste ipotetice surse vor fi fost scrise chiar cu slove chirilice, după cum sugerează cîteva erori de literă (notarea, spre exemplu, a lui $p$ latin în loc de $r$ în fena $p$ pentrufenar 'fînar').

Ansamblul lucrării, numărul mare de intrări românești pentru care nu este indicat un echivalent latinesc, ca și marele număr de regionalisme bănățene înregistrate arată însă că Dictionarium ValachicoLatinum este o lucrare lexicografică integral originală.

\section{Relevanța lingvistică și culturală a textului}

Această primă lucrare lexicografică de mare întindere cu bază limba română realizată în spațiul românesc, intitulată Dictionarium Valachico-Latinum, are astfel o importanță aparte în istoria scrisului nostru literar.

Autorul manuscrisului alcătuit cîndva în jurul anului 1650 (exact în perioada în care Mardarie Cozianul realiza Lexiconulslavo-românesc și tîlcuirea numelor pe baza tipăriturii lui Pamvo Berînda) se dovedește un foarte bun cunoscător deopotrivă al limbii latine (a înregistrat uneori forme, grafii și semnificații rar atestate în textele latinești ale vremii) și al limbii române, aceasta din urmă atît în forma ei literară, elevată, cît și în aceea specifică, la mijlocul secolului al XVII-lea, vorbirii locale bănățene (inclusiv în variantele familiară sau argotică).

Între cuvintele românești consemnate se individualizează, după cum s-a remarcat chiar din momentul descoperirii manuscrisului (în vara anului 1871), un corpus extrem de bogat de regionalisme. Acestea provin în primul rînd din limba maghiară (acar adverb, băsău, celşag, feștic, harîng, lacşă, megheleu, nosa, ocoș, păharsec, ratot, șod, tiucă, țipou, vișeu ș.a.) sau din limba sîrbă (babiță, coprenă, dică, faidă, gîrclean, ialoviță, lovet, mătrac, opreg, pruglă, rîză, stăci verb, știm, treasc, ureznic, vîrcă, zglăvoace ș.a.).

Mai multe cuvinte sînt preluate din limbă vorbită a vremii, uneori din varianta familiară sau chiar din cea argotică a acesteia (foflei, răsipilă, rumega 'a medita, a socoti', căcîcea, cenuşotcă, pişotcă), iar unele structuri lexicale, specifice tot limbii vorbite, au fost foarte probabil create de vorbitori prin etimologie populară (precum simțivară 'pițigoi').

Cele mai numeroase forme-titlu sînt însă, în mod firesc, cuvinte vechi, moștenite din latină. În cazul unora dintre acestea, glosele latinești atestă prezența în uzul local a unor sensuri moștenite, considerate dispărute încă din veacul anterior, dar rămase specifice nordului Dacoromaniei, după cum dovedesc textele noastre vechi (a se vedea, în acest sens, număra 'a citi' și derivatele numărător 'cititor' și numărătură 'citire').

Multe intrări reprezintă apoi (prin raportare la formele înregistrate în dicționarele istorice ale limbii române) prime atestări (cocoșter, glonț 'sferă', întrupura, rit 'cioc', strepede, tăfaragă, tic 'cioc', toblă, urechelniță 'insectă; aparat pentru curățat urechile', vintă ș.a.), care permit coborîrea în timp a datărilor cunoscute

\footnotetext{
${ }^{9}$ A se vedea în primul rînd studiile reunite în Király (2003, p. 9-130).
} 
pentru unele forme și variante lexicale. Iar alte cuvinte-titlu, între care crîmpicea 'soi de grîu', bronț 'os moale', lingui 'a se linguși', necît 'decît', păninc 'părînc, (varietate de) mei', scopos 'în mod demn, cum se cuvine', tristeală 'tristețe', ursoanie 'ursoaică, veșt '(om) încercat, cu experiență' sau zogonitor 'izgonitor', lipsesc din dicționarele istorice ale limbii noastre. La fel cum lipsesc multe dintre numele de plante, îndeosebi de pomi fructiferi, cîmp lexical extrem de bine reprezentat ${ }^{10}$. (Sînt consemnate în Dictionarium 15 soiuri de măr, 13 de păr și 4 de cireș).

Influența exercitată de limba latină, remarcabilă într-o epocă în care scrisul românesc era dominat de modele slavone, a avut consecințe și în stabilirea inventarului lexical, întrucît între formele-titlu din Dictionarium apar, datorită culturii autorului textului și, desigur, sub influența vorbirii elevate a vremii, mai multe neologisme cu etimon latinesc sau/ și grecesc (artic, lăternă, mil 'milă, măsură pentru distanță, mirac, mod, probă, stemă, sumă, tipar, titor 'tutore', violă 'viorea' ș. a.), respectiv calcuri după cuvinte latinești (întrîmbla 'a media', întrîmblare 'mediere', întrîmblător 'mediator', neștinție 'neștiință).

Cele mai semnificative influențe latinești se remarcă însă în ortografierea cuvintelor-titlu. Ne referim în primul rînd la mai multe abateri semnificative de la normele scrisului maghiar, dominante în cadrul textului (între acestea utilizarea lui $c$ și a lui $c h$ în loc de $k$ sau crearea unor grafeme pentru notarea unor sunete ale limbii române: $a ̉$ și $e ̉$ pentru notarea vocalei centrale, sh pentru notarea lui $[s],, d s h$ pentru notarea lui $[\breve{g}])$. Avem însă în vedere, în mod special, utilizarea frecventă a unor grafii de tip etimologizant, ce dovedesc cunoașterea de către autorul anonim a legăturii existente între unele cuvinte românești și echivalentele lor latinești (a se vedea, spre exemplu, utilizarea literelor duble ff în afflu, $m m$ în summă sau $t t$ în guttă) sau pun în evidență descendența unor derivate sau a unor forme gramaticale dintr-un anume cuvînt de bază românesc (ca în cazul grafemelor inovatoare $g s$, ts sau $t z$, utilizate în zelogsie, zelogsit, prin corelație cu zelog, sau în berbetzie, clopotzel, prin corelație cu berbat și clopot).

Iar competența lingvistică a intelectualului care a redactat Dictionarium Valachico-Latinum este confirmată o dată în plus de încercarea de diferențiere prin forma-titlu a unor omonime (a se vedea perechi de tipul scos - scosul, trecut - trecutul, unde formele marcate prin articol sînt totdeauna adverbe), dar în special de prezența în manuscris a unor prime încercări de normare explicită a uzului, prin corelarea unor variante fonetice, înregistrate (firesc) fără glosă, cu forme considerate recomandabile (unele variante cu $s v$ sau $z$ sînt trimise prin vide la formele cu sf : svădesc vide sfädesc, svîrșesc vide sfîrşesc, respectiv la formele cu $d z$ : zac vide $d z a c$, zară vide $d z$ ară $)$.

\title{
4. Considerații finale
}

Destinat foarte probabil nu unui scop didactic (deprinderea unei limbi străine de cultură, în acest caz latina, prin intermediul românei) și nici unuia practic (ca instrument ajutător pentru traducerile din limbile de cultură ale vremii în limba română), ca majoritatea lexicoanelor vechi românești cu model slavon, ci prezentării cît mai detaliate a vocabularului limbii române cu ajutorul glosării prin latină, Dictionarium Valachico-Latinum ocupă astfel o poziție aparte în rîndul vechilor scrieri lexicografice românești.

Caracterul particular al acestui prim dicționar original al limbii noastre este susținut deopotrivă de raportarea, pentru prima dată într-o scriere lexicografică originală, la modelul latinesc (în timp ce alte scrieri românești contemporane preluau, prin traducere, sau prelucrau modele slavone) și de crearea, respectiv de utilizarea sau de recomandarea unor forme sau a unor grafii, ca formă incipientă de normare literară.

\section{Bibliografie}

\author{
A. Izvoare \\ Catalogus 1850 = Catalogus manuscriptorum <Bibliothece Regie Scientiarum Universitatis $>$, confectus circa annum 1850, [Pest, \\ $1850]$. \\ Catalogus 1877 = Catalogus manuscriptorum que in Regie Scientiarum Universitatis Bibliothece Archivio Pestini observantur, \\ [Pest, 1877].
}

\footnotetext{
${ }^{10}$ Vezi, pentru lista integrală a numelor de plante cuprinse în Dictionarium Valachico-Latinum, Chivu (2010, p. 333-340).
} 
Catalogus 1889 = Catalogus librorum manuscriptorum Bibliothece Regie Scientiarum Universitatis Budapestiensis, [Tomus I], Budapest, 1889.

Chivu, Gh. (2008). Dictionarium Valachico-Latinum. Primul dicționar al limbii române. Studiu introductiv, ediție, indici și glosar de , Editura Academiei Române, București, 2008.

\section{B. Lucrări de referință}

Chivu, Gh. (2003). Anonymus Caransebesiensis - manuscris românesc de la mijlocul secolului al XVII-lea, în „Limbă şi literatură", I-II, p. 21-27.

Chivu, Gh. (2010). Nume de plante în Vocabularium Valachico-Latinum, în Limba română. Controverse, delimitări, noi ipoteze. Actele celui de al 9-lea Colocviu al Catedrei de limba română, I, Editura Universității din București, p. 333-340.

Crețu, G. (1898). Anonymus Caransebesiensis. Cel mai vechi dicționar al limbei române, după manuscriptul din Biblioteca Universității din Pesta, în „Tinerimea română”, I, p. 320-380.

Hasdeu, B. P. (1871). Două descoperiri, în „Columna lui Traian”, II (30), p. 117.

Hasdeu, B. P. (1891). Anonymus Lugoshiensis. Cel mai vechi dicționar al limbei române, după manuscriptul din Biblioteca Universității din Pesta, în „Revista pentru istorie, archeologie şi filologie”, VI, p. 1-48.

Iordan, I. (coord.) (1978). Istoria lingvisticii românești, Editura Științifică și Enciclopedică, București.

Király, F. (2003). Mihail Halici-tatăl, Dictionarium Valachico-Latinum [Anonymus Caransebesiensis]. Studiu filologic și indice de cuvinte de , ediție îngrijită de Alexandru Metea și Maria Király, Editura First, [Timișoara].

Seche, M. (1966). Schiță de istorie a lexicografiei române, I, Editura Științifică, București.

Tagliavini, C. (1930). Il „Lexicon Marsilianum”. Dizionario Latino-Rumeno-Ungherese del. Sec. XVII, Studio e testo, Cultura Națională, București. 